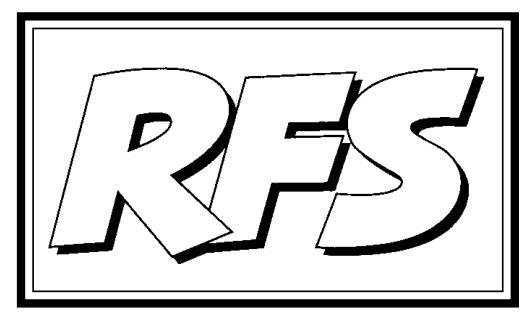

Revista de Fomento Social, 56 (2001), 627-647

\title{
Migraciones y desarrollo: ¿Hay lugar para la cooperación?
}

Marta ARIAS ROBLES ${ }^{2}$

Las migraciones no son, ni mucho menos, un fenómeno novedoso del siglo XXI. De hecho, han sido una constante en la historia de la especie humana, desde los primeros desplazamientos de población en búsqueda de alimentos y cobijo hace más de 100.000 años. Históricamente, el mayor incremento de las migraciones, tanto en cifras absolutas como en relativas, se produjo en los cien años siguientes a 1815. Hoy en día las migraciones afectan aproximadamenteal $2 \%$ de la población mundial, poco más de lo que ésta crece en un año. Sin embargo, no podemos negar que las migraciones que se producen hoy son muy diferentes de las del siglo pasado. Los profundos cambios ocurridos en el escenario mundial en las últimas décadas cuestionan muchos de los viejos paradigmas de interpretación de nuestras sociedades y van gestando

1 El presente artículo es un resumen del estudio publicado con el mismo título en el informe La Realidad de la Ayuda 2001-2002, Colección Informes nํ19, Intermón OXFAM.

2 Técnico del Departamento de Estudios de Intermón OXFAM. 
la emergencia de otros nuevos. Los procesos de desregulación estatal y la construcción de entidades supranacionales, entre otros fenómenos contemporáneos, han vuelto cada vez más confusas las fronteras entre Estadosnación, generando una nueva interdependencia e interconexión a nivel mundial. Pero los niveles de integración son muy desiguales en función del ámbito de actuación que analicemos. En el terreno económico, la globalización ha marcado una reestructuración de las relaciones internacionales en las que el sector financiero funciona efectivamente como una unidad en tiempo real. Frente a esto, un área teóricamente tan representativa de la globalización como la libertad de circulación, funciona hoy con plenitud tan sólo en lo que se refiere a los movimientos de capital. La libre circulación de mercancías no ha pasado aún de ser un paradigma que se cumple con una asimetría espectacular (muchos países del Sur se han visto forzados a abrir por completo sus fronteras, a pesar de que las políticas proteccionistas de Estados Unidos y la Unión Europea aún no han sido desmanteladas), mientras que, sin lugar a dudas, la libre circulación de las personas es uno de los aspectos más inacabados del proceso actual ${ }^{3}$.

Frente a esto, la misma dinámica de la globalización está conllevando la organización a escala planetaria de la producción y gestión de bienes y servicios. Hace unos años, surgía con fuerza el fenómeno de la deslocalización de las grandes empresas, que trasladaban una parte importante de sus cadenas de producción a países del Sur donde podían conseguir una rebaja importante en los costes (salarios más bajos, menores exigencias sociales y medioambientales, etc.). En el momento actual, este proceso -que continúa- se ve acompañado por el surgimiento en los propios países del Norte de los denominados "mercados de trabajo duales", en los que se manifiesta una significativa demanda de trabajadores dispuestos a aceptar los trabajos más precarios, los salarios más bajos y las condiciones más desventajosas. Los inmigrantes sin documentación, necesitados imperiosamente de los recursos, temerosos de ser descubiertos y sin posibilidad de recurrir a las vías formalmente establecidas para proteger sus derechos como trabajadores, se constituyen en fuente prioritaria de esta mano de obra-aunque no exclusiva, dado que en general el conjunto de la población inmigrante, con y sin papeles, puebla de manera creciente este segundo mercado-.

Otro aspecto de la globalización que tiene importantes repercusiones en

3 En palabras de un funcionario del FMI, "La migración internacional representa la gran ausencia del proceso de globalización". FAINI (2001). 
los procesos migratorios actuales tiene que ver con la revolución tecnológi$\mathrm{ca}$, fundamentalmente en el ámbito de los transportes y las telecomunicaciones. Por lo que respecta a los transportes, es evidente que las mayores facilidades para trasladarse de una manera más rápida y con un menor coste han reducido las dificultades planteadas a la hora de viajar a otro país, fundamentalmente en los casos de mayor distancia física. Por otra parte, el desarrollo de las telecomunicaciones está generando la emergencia de una cultura homogénea glo bal que propicia la circulación y expansión de productos, hábitos y costumbres.

Este tipo de fenómenos (demanda de mano de obra, desarrollo económico, etc.) forman parte del denominado "efecto atracción" en los países del Norte, que se complementa con un paralelo "efecto expulsión" en el Sur, estrechamente relacionado con las situaciones de desigualdad, pobreza y conflictos de todo tipo que se producen en las zonas de origen de los emigrantes y que se multiplican en aquellos países o regiones que se ven excluidos del actual sistema global.

\section{1. "Allí se vive mejor". La decisión de salir}

El estudio de las vinculaciones entre migraciones y desarrollo debe pasar por el análisis de los factores, el contexto y las motivaciones que se encuentran detrás de la decisión de partir. Una decisión en la que se conjugan situaciones más o menos objetivas con otras mucho más subjetivas, vinculadas con la situación personal del migrante (no podemos olvidar que, en último caso, la migración forma parte de un proceso de toma de decisión personal y/o familiar). Existen también importantes diferencias sociales y culturales entre unas regiones y otras, conformando realidades distintas que ejercen por su parte una influencia importante en el fenómeno migratorio.

A continuación exponemos algunos de los aspectos más significativos a tener en cuenta a la hora de comprender dichos procesos:

- El factor económico

A pesar de que, en su mayor parte, los inmigrantes que llegan a nuestras fronteras no provienen de los países más pobres ni de las capas más desfavorecidas de sus comunidades de origen, parece innegableque el factor económico constituye probablemente (aunque, como veremos, no de mane- 
ra exclusiva) la motivación más poderosa que impulsa a muchas personas a abandonar su país. El inmigrante como individuo suele ser un sujeto que se traslada a residir a otro país para trabajar y mejorar su situación económica ${ }^{4}$. Más allá de las situaciones personales, el aspecto económico se encuentra presente de una manera muy relevante (bajo la forma de crisis o procesos de recesión e inestabilidad agudos) en determinados procesos migratorios que han experimentado un crecimiento significativo en los últimos años.

Sirva de ejemplo el caso de Ecuador, país que atraviesa desde el año 1999 una grave crisis que ha constituido uno de los principales factores desencadenantes del incremento de la emigración a Norteamérica y Europa. Así, ha pasado de ocupar un discreto décimo puesto entre las comunidades de origen de inmigrantes en España en el año 1998 al tercer puesto en la actualidad. En este mismo periodo, el PIB nacional cayó en un 31\%, mientras el país atravesaba la etapa de empobrecimiento más acelerada de toda la historia de América Latina (los pobres pasaron de 3,9 a 8,4 millones de personas y la extrema pobreza subió del 12 al $21 \%$ en todo el país). Tan sólo en el periodo que va desde enero a agosto del año 2000 fueron casi 70.000 los ecuatorianos que se desplazaron a España. Apenas 3 años antes, en 1997, la cifra total no alcanzaba las 11.000 personas.

La vinculación de la crisis económica con el proceso migratorio tiene lugar no sólo a través del deterioro efectivo de las condiciones de vida, sino a través de un factor mucho más subjetivo, una sensación de "pesimismo colectivo" y desconfianza en las posibilidades del país de salir adelante. A este segundo elemento contribuye en buena medida un generalizado sentimiento de decepción ante el papel del gobierno y las instituciones estatales, lo que acentúa aún más el proceso de búsqueda de alternativas individuales para afrontar la situación.

Por otra parte se hace necesario tener en cuenta otra serie de aspectos, presentes en la inmensa mayoría de los países de origen de flujos migratorios, que han tenido o están teniendo una incidencia importante desde el punto de vista socioeconómico como generadores del mencionado "efecto expulsión". Así por ejemplo, en la actualidad se reconoce de una manera casi unánime (y no sólo por ONG, sino por instituciones como las agencias de Naciones Unidas) que los programas de ajuste impulsados por el Banco Mundial y el FMI han tenido un profundo impacto, a menudo negativo, sobre

4 E. Ramírez (1996). 
el empleo y las condiciones de vida de millones de personas en los países más pobres ${ }^{5}$. A través de estos programas, por poner un ejemplo, se ha impuesto una liberalización comercial que ha expuesto a los ya de por sí débiles sistemas agrícolas e industriales de estos países a la competencia desleal del mercado internacional. Este fenómeno, unido a las medidas proteccionistas de mercados como el europeo o el norteamericano, ha generado una necesidad permanente de abaratar los costes (económicos y sociales) de producción.

En relación con lo anterior, sería también interesante analizar el papel del sector privado, nacional e internacional, en el fomento de un modelo de desarrollo sostenible o, por el contrario, en la generación de más situaciones de empleo precario e inversión no productiva. Así por ejemplo, numerosos procesos de privatización, particularmente en países de América Latina, se han llevado a cabo (bajo la presión una vez más del Banco Mundial y el FMI) sin tener en cuenta las repercusiones sociales que podían tener y sin exigir unas condiciones mínimas a la actuación de las empresas compradoras. Otros sectores empresariales, como es el caso de la empresa extractiva (petróleo, minas, gas natural) han sido tradicionalmente acusadas de propiciar (o al menos no evitar debidamente) situaciones muy graves de violaciones de los Derechos Humanos y medioambientales de grupos importantes de población, que se han visto forzados a desplazarse a otras ubicaciones.

- Huyendo de las persecuciones: refugiados y desplazados internos

Todos los días, hombres y mujeres toman la terrible decisión de abandonar su hogar, su comunidad o su país porque tienen miedo de perder la vida. Pocos pueden permitirse escapar en avión, la mayoría se echa a la carretera, con las pocas pertenencias que pueden transportar a pie, en dirección a la frontera más cercana.

Huyen de la guerra, aterrados por el miedo a sufrir un ataque o a verse atrapados por el fuego cruzado. Huyen de la persecución, de la cárcel, la tortura o la ejecución. Sus temores nacen del sufrimiento presente, de las amenazas reales o de las experiencias de sus amigos y vecinos. También los hay que son blanco de la persecución por su origen étnico, su idioma o su religión.

5 P. Stalker (2000). 
Cada nuevo refugiado es consecuencia de un gobierno que comete, tolera o es incapaz de impedir las violaciones de derechos humanos. Los veinticinco millones de refugiados del mundo según las estimaciones del Alto Comisionado de las Naciones Unidas para los Refugiados (ACNUR), representan un dedo acusador que señala a los gobiernos del mundo. Veinte millones más de seres humanos son desplazados internos: se han visto obligados a abandonar sus hogares, pero permanecen dentro de su país de origen ${ }^{6}$.

Las naciones desarrolladas -y el conjunto de la llamada "Comunidad Internacional"- tampoco cumplen su parte de responsabilidad apoyando a los países más deprimidos, que paradójicamente, reciben el noventa por ciento del total de los refugiados del mundo. Puesto que hablamos de un problema global, es necesario que se repartan entre todos los países los costos y las responsabilidades que conlleva la protección de los refugiados.

- El entorno social y el factor psicológico: la cultura migratoria

Si bien los dos factores que acabamos de analizar constituyen probablemente las motivaciones más frecuentes de los procesos migratorios, debemos tener en cuenta que casi nunca se producen en solitario. Además, es importante considerar la influencia de factores de tipo social y psicológico que, combinados con los anteriores, llevan a determinados sujetos a tomar la decisión de abandonar su lugar de origen (sea para desplazarse del campo a la ciudad o para trasladarse a otro país).

Por lo que respecta al contexto social, podemos tomar como ejemplo el caso de la mujer marroquí. Inicialmente excluidas como sujeto activo del proceso migratorio (los que salían eran los hombres), los últimos años han sido testigos de una feminización de los flujos, motivada en parte por los procesos de reagrupación familiar, pero nutrida igualmente por una salida creciente de mujeres que presentan otro tipo de aspiraciones y motivaciones. La perspectiva de acceder a una mayor autonomía e incrementar su participación en la vida pública (en definitiva, de modificar su papel en la sociedad) constituye un atractivo adicional a la motivación económica.

Por otra parte, ya hemos mencionado antes cómo además de los factores

6 Según la Convención de Ginebra de 1951 sobreel Estatuto de los refugiados, estos últimos son los que "se encuentran fuera del país de su nacionalidad" o, "careciendo de nacionalidad (...) fuera del país donde antes tuviera su residencia habitual". 
más o menos objetivos que afectan a la decisión de emigrar, es fundamental la percepción que ésta puede tener tanto de su propia situación y perspectivas como de las del conjunto del país. En este aspecto, juega un importante papel el imaginario colectivo, los círculos familiares y sociales que refuerzan la idea de la migración como el único instrumento de supervivencia y un terreno donde se disputa el reconocimiento social ${ }^{7}$.

La emigración en estos contextos pasa a percibirse como un triunfo, lo cual en algunos casos llega a constituir una presión psicológica nada desdeñable sobre el emigrante. En efecto, estos a menudo se encuentran en su llegada al destino con una realidad muy distinta (y generalmente mucho más dura) de lo que había imaginado. Sin embargo, se sienten incapaces de admitir lo que sería visto como una derrota, y contribuyen a transmitir una idea falseada que acaba perpetuando un círculo vicioso de desinformación y desengaño. De hecho, el mito del emigrante triunfador constituye en muchas comunidades un aliciente importante para los más jóvenes.

Este mito se refuerza a su vez con la imagen que se tiene de los países de destino. El concepto de desarrollo, progreso, bienestar, asociado a las ventajas comparativas de las diferencias salariales, y por tanto en la calidad de vida de esos países operan como mecanismos de atracción para la población.

\section{Migraciones: oportunidades y amenazas para el desarrollo}

Una mirada amplia al fenómeno de las migraciones que profundice en sus potenciales efectos, positivos o negativos, tanto para la comunidad inmigrante como para la de acogida, puede ayudar a identificar de qué forma la cooperación al desarrollo puede contribuir a potenciar sus oportunidades y minimizar las amenazas.

7 Aunque este aspecto es muy difícil de reflejar en cifras y relaciones causa-efecto concretas, es fundamental tenerlo en cuenta a la hora de plantear determinadas acciones (incluida la ayuda al desarrollo) que pretenden supuestamente provocar de una manera casi inmediata una modificación de los patrones migratorios. Aunque algunas situaciones de contexto puedan cambiar de una manera más o menos rápida (fin de un conflicto, cambio de gobierno o condonación sustanciosa de la deuda externa) las percepciones colectivas varían de una manera mucho más lenta y no siempre ofrecen las reacciones esperadas. 
- Las remesas: una fuente de recursos de importancia creciente

Los recursos enviados por los emigrantes a sus familias de origen han constituido tradicionalmente una parte importante de las estrategias de supervivencia de muchas familias en todo el mundo y han tenido una contribución relevante al equilibrio de las balanzas de pagos de sus países. Cada vez más, el impacto social y económico de este fenómeno trasciende el ámbito familiar y está atrayendo la atención de gobiernos, instituciones financieras y agencias de desarrollo.

A pesar de que resulta difícil conseguir cifras fiables acerca del volumen real de remesas (a menudo muchos emigrantes las envían por diversas vías informales, sea a través de conocidos, en sus propios viajes anuales, etc.), lo cierto es que todos los estudios calculan que los montos actuales, situados en torno a los 70.000 millones de dólares al año, superan los niveles internacionales de Ayuda Oficial al Desarrollo. Es decir, las redes de ayuda familiar establecidas con las migraciones superan la cuantía de la solidaridad internacional establecida entre las naciones y agencias intergubernamentales.

Por regiones, probablemente es el caso latinoamericano el que esté más documentado. Estudios recientes del Banco Interamericano de Desarrollo calculan que los flujos de remesas a la región superaron los 20.000 millones de dólares en el año 2000. Esta cantidad, además de superar como hemos dicho los niveles de AOD, equivale aproximadamente a un tercio de la Inversión Extranjera Directa, supone al menos un 10\% del PIB en 6 de los países estudiados (Ilegando al $17 \%$ en el caso de Haití) y supera el $150 \%$ del valor de los intereses pagados por la región en concepto de deuda externa durante los últimos cinco años.

Para valorar el papel que las remesas pueden jugar como herramientas de desarrollo, es importante tener en cuenta algunas consideraciones:

- La evolución de las remesas no es lineal; a medida que los inmigrantes se establecen en el país de destino, sobre todo si pueden reagrupar a su familia, aumentan sus gastos en dicho país y pierden vínculos con su comunidad de origen.

- Su recepción no está garantizada de manera permanente, puesto que las posibilidades laborales de los inmigrantes suelen ser intermitentes, haciendo que su situación económica sea inestable.

- El coste de transacción del envío de dinero suele ser muy elevado, 
rondando según algunas estimaciones entre el 15 y el $20 \%$ de los fondos enviados.

- Una parte importante de las remesas acaba en manos de los prestamistas, destinada a cubrir el pago de la deuda contraída en el país de origen.

- Las remesas constituyen fundamentalmente parte de una estrategia familiar de supervivencia. Se trata de unos recursos totalmente privados so bre los que el emigrante, conjuntamente con su familia en el lugar de destino, tiene plena potestad.

Como consecuencia directa de este último punto, no es de extrañar que todos los estudios realizados sobre el uso habitual de las remesas apunten a que la mayor parte de las mismas se destine al consumo inmediato de las familias, con un énfasis particular en la alimentación y la educación de los más pequeños. En los casos de las familias más pobres, no existen opciones adicionales, puesto que el dinero que llega del emigrante, una vez que se ha pagado la deuda, apenas cubre los gastos de la familia y no llega a cubrir la canasta básica.

Aunque es innegable que esta distribución del gasto tiene de hecho diversos efectos positivos para la economía en su conjunto (entrada de divisas, incremento del consumo doméstico, dinamización del sector de la construcción, generación de empleo, etc.), la valoración más extendida es que por el momento, el envío de remesas está muy lejos aún de desarrollar con plenitud su potencial productivo. Este hecho tiene que ver con diversos factores, que pueden ser de tipo individual (falta de información y formación suficiente), social (ausencia de una cultura de ahorro) o estructural (escasas facilidades para la inversión y desconfianza en las instituciones).

Frente a estas dificultades, resulta interesante comprobar la existencia de algunas experiencias puntuales, las denominadas "remesas colectivas", enviadas por asociaciones de inmigrantes a sus localidades de origen, con el objetivo de llevar a cabo diversos proyectos identificados conjuntamente con asociaciones del lugar. A pesar de lo limitado (en términos cuantitativos) de estas experiencias, y reconociendo que no se puede esperar que tengan un impacto a nivel nacional o global a la hora de canalizar el uso de las remesas, incluyen algunos elementos muy positivos, tales como el hecho de que la iniciativa parta de los propios emigrantes, su papel a la hora de reforzar los vínculos entre la comunidad emigrante y la de origen, o para facilitar la transferencia de conocimientos y capacidades adquiridas por los migrantes en las comunidades de destino. 


\section{- Fuga de cerebros}

Pero el efecto positivo que puede tener para un país la entrada de recursos con motivo de la emigración de sus habitantes suele conllevar un alto precio: la salida masiva de población joven, formada y emprendedora de un país supone sin lugar a dudas una pérdida de enormes dimensiones cuyo coste real resulta muy difícil de cuantificar.

Existen estudios que estiman que Africa Subsahariana perdió como consecuencia de la emigración el 30\% de su población formada entre 1960 y 1987. Resulta impactantetambién conocer las cifras proporcionadas por Naciones Unidas, según las cuales existen más médicos en Francia procedentes de Senegal que en todo el país africano. Según la misma agencia, en Francia existe un médico por cada 300 habitantes, mientras que en Senegal la proporción alcanza las 18.000 personas. En el caso de Ghana, más del 15\% de la población nacional que ha tenido acceso a la formación terciaria ha emigrado a los Estados Unidos. En Guatemala y la República Dominicana ${ }^{8}$, casi 3 de cada 10 personas con formación secundaria ha hecho lo mismo.

El caso de los Estados Unidos es particularmente significativo porque, a diferencia de las políticas restrictivas que están aplicando otros gobiernos de la OCDE, en este país se ha incentivado tradicionalmente la inmigración de fuerza de trabajo capacitada, siendo especialmente notorio el caso de los trabajadores de la India en el ámbito de la informática y las nuevas tecnologías. Frente a esto, nos encontramos con casos como el de España, en el que la oferta laboral (y por tanto las posibilidades de regularización en función de la política de cupos) para los inmigrantes no comunitarios se concentra en unos ámbitos muy delimitados (tradicionalmente servicio doméstico, hostelería y agricultura) que dificultan que aquellos que han tenido acceso a otro tipo de formación puedan desempeñar su carrera. Esta circunstancia se agrava con las dificultades que se presentan a la hora de proceder a la homologación de estudios para poder ejercer sus carreras por cuenta propia en nuestro país. En la práctica, se produce una devaluación socioprofesional que contribuye decisivamente al malestar psíquico y social de algunos colectivos y cuestiona seriamente uno de los beneficios potenciales de la emigración para el país de origen, como es el de la formación de la población emigrante a través del desempeño de su trabajo.

8 Un estudio sobre el colectivo dominicano en Cataluña determinó igualmente que el 52\% de los inmigrantes residentes en dicha comunidad en 1998 habían tenido acceso a la educación secundaria, cuando la media nacional era del $23 \%$.

\section{RFS}


- La emigración como válvula de escape

En algunos contextos se comienza a hablar de las migraciones como la "válvula de escape" o el "salvavidas" de la globalización, en el sentido de que la salida de población proporciona a los países de origen ciertos "respiros" ante situaciones que de otro modo tal vez resultarían insostenibles política, social o económicamente.

Así, en un país como Ecuador, las cifras de desempleo han experimentado un descenso en los últimos meses, lo cual puede ser interpretado como el fruto de un buen desempeño económico. Sin embargo, el hecho de que la emigración neta del país supere el $10 \%$ de la población económicamente activa tiene más que ver con este resultado que una recuperación económica desafortunadamente inexistente. Es particularmente interesantela situación de la ciudad ecuatoriana de Cuenca, donde se registra desde hace muchos años la mayor salida de migrantes. Allí los niveles de desempleo y subempleo han descendido a niveles inferiores a los existentes antes del comienzo de la crisis ${ }^{9}$.

Del mismo modo, la salida masiva de población formada, proveniente de las clases medias, está suponiendo un descenso de la presión social y un debilitamiento de la capacidad de movilización de muchas organizaciones, que ven como no pocos de sus miembros más activos abandonan el país. Siguiendo con el caso ecuatoriano, este fenómeno está favoreciendo en alguna medida el resurgir del movimiento indígena, dado que su población presenta unos índices de emigración mucho menores.

La emigración puede constituir también una válvula de escape desde la perspectiva de las relaciones de género, al favorecer un importante cambio en el status social de la mujer tanto en el seno de su familia como ante la sociedad ${ }^{10}$. Para muchas de ellas, la emigración supone pasar a ser un agente económico importante en su entorno y se convierteen un medio deconquista de autonomía.

9 A. Acosta (2001).

10 Ver a este respecto publicaciones diversas de Á. Ramírez (1999), como "Le valeur du travail. L'insertion dans le marché du travail des immigrés marocaines en Espagne". REMI Revue Européenne des Migrations Internationales, vol. 15, no 2. París, pp. 9-36. 
- La modificación familiar: el surgimiento de la familia transnacional

En estrecha relación con el apartado anterior, debemos tener en cuenta que la emigración está teniendo un efecto muy relevante en la configuración de la familia en los países de origen, en la medida en que, como ya se ha mencionado, la decisión de emigrar forma parte con frecuencia de una estrategia familiar. El proceso tiene numerosas implicaciones, que van de lo económico (es el conjunto de la familia la que moviliza los recursos necesarios) a lo más puramente afectivo.

En efecto, la emigración supone en muchos casos la separación de los diversos miembros de una familia, incluyendo el cuidado de los hijos por los abuelos u otros familiares, y desemboca a menudo en separaciones y hogares desestructurados.

En general, en muchos países ha surgido una nueva figura, la de la "familia transnacional", con miembros repartidos por diversos países, cuyo sistema de vida dista cada vez más de la concepción de la familia tradicional. Generalmente, estas mismas familias se constituyen en una parte relevante del circuito migratorio, contribuyendo de manera colectiva a la obtención de los recursos necesarios para la partida, poniendo en marcha su circuito de contactos para la acogida del recién llegado y, en buena medida, retroalimentando el proceso migratorio más allá de las motivaciones inicialmente planteadas.

Finalmente, otros aspectos relacionados con el impacto de la emigración sobre el ámbito familiar incluyen el desplazamiento de familias originarias de zonas rurales hacia las ciudades, donde se han adquirido nuevas propiedades inmobiliarias como recurso para invertir algunos de los fondos enviados por el emigrante. Las familias se insertan así en un nuevo espacio, lo cual implica en ocasiones una mejora social que les permite desarrollar un nuevo proyecto de vida. Como aspecto menos positivo, este proceso multiplica el fenómeno urbanizador que ya se venía produciendo en muchos países en desarrollo, con importantes consecuencias sociales y medioambientales que deben tenerse en cuenta.

\section{El papel de la cooperación al desarrollo ante las migraciones}

A medida que se ha ido avanzando en el análisis de las vinculaciones entre migraciones y desarrollo ha ido surgiendo un nuevo concepto, codesarrollo, que parte de la necesidad de reflejar esta interrelación de una manera tangible en las políticas concretas de inmigración y cooperación. En su 
esencia, este concepto incluye la consideración de que las migraciones se pueden convertir en fuente de desarrollo y progreso social, tanto para el país de destino como para el de origen.

La iniciativa que ha llegado más lejos en su puesta en práctica ha tenido lugar en Francia. Centrada por el momento en tres países (Marruecos, Senegal y Mali), pretende acoger a contingentes de personas, para que se formen trabajando en Francia con vistas a un regreso programado a su país, de manera que se articulen las necesidades de los países de destino y de origen. Su puesta en marcha, sin embargo, está atravesando por serias dificultades, y ha sido criticada con dureza por algunos autores al considerar que se trata de una manera encubierta de promover el retorno de los emigrantes a sus países.

En cualquier caso, más allá de las discusiones teóricas sobre el concepto de codesarrollo, lo cierto es que tradicionalmente las políticas de cooperación internacional han tendido a prestar poca atención a la contribución de las migraciones a la reducción de la pobreza. 0 bien ignoran el fenómeno migratorio, o bien incluyen como objetivo más o menos explícito la reducción de flujos.

Frente a esto, conviene plantear de partida los siguientes principios:

- La Ayuda Oficial al Desarrollo no es una alternativa a la inmigración y no debe plantearse como tal. La cooperación al desarrollo es una actividad que tiene un valor esencial per se, que obedece a unas dinámicas propias de redistribución y justicia social y que no puede plantearse como un instrumento encaminado a conseguir fines egoístas para los países donantes.

- La Ayuda no tiene por qué reducir las migraciones, al menos en una primera etapa. Primero porque la ayuda supone un refuerzo de vínculos entre las dos comunidades que puede alentar a más personas a salir hacia el lugar del que llegan los recursos. Y segundo porque una mejora de las condiciones materiales no garantiza la superación de los aspectos sociales y culturales que hemos comentado tienen una gran influencia en los procesos migratorios. Si mejora su situación económica, la población que lleva tiempo deseando emigrar tendrá un acceso más fácil a los recursos y oportunidades necesarios para hacerlo.

- No es cierto que todas las acciones de cooperación al desarrollo ejerzan un efecto positivo sobre las migraciones. Determinados tipos 
de ayuda pueden resultar irrelevantes en el contexto de las migraciones, en el sentido de que no contribuyen a generar opciones distintas para la población que se está planteando emigrar, ni aportan nuevas vías para que el fruto de esas migraciones revierta en el desarrollo de la población de origen.

- No se puede aceptar la utilización de la ayuda y de las migraciones como una herramienta de presión en las negociaciones políticas entre países.

Pero estas premisas no deben hacernos llegar a la conclusión de que no hay un lugar para la cooperación al desarrollo en el contexto de las migraciones. La política de inmigración en un país dado se puede convertir en su conjunto en una herramienta para la cooperación al desarrollo de los países de origen. Además, la cooperación puede contribuir a generar una mayor variedad de opciones para aquellos que, sin desear emigrar, se ven forzados a ello. Por último, a través de la cooperación se pueden acompañar los procesos migratorios, de modo que se aproveche su enorme potencial de cambio en beneficio de la comunidad de origen.

Con el fin de integrar de una manera más efectiva el fenómeno migratorio, la cooperación internacional podría dar los siguientes pasos:

Analizar. Realizar estudios, país por país, de los factores concretos que se encuentran detrás de los procesos de salida, motivaciones principales, efectos positivos y negativos de las migraciones sobre los migrantes y sus comunidades, etc.

Escuchar. Crear vías de comunicación y colaboración entre los agentes de cooperación al desarrollo y las asociaciones de inmigrantes en los países donantes. Ellos constituyen un puente privilegiado entre las dos culturas, entre lo micro y lo macro, que puede ser de gran utilidad a la hora de anclar los programas en la realidad de los países.

Evaluar la cooperación al desarrollo. ¿Está contribuyendo la cooperación al desarrollo a generar opciones para los que desean permanecer en sus países?, ¿está generando espacios para que aquellos que deseen regresar puedan tener acceso a una vida digna?

Coordinar. Avanzar hacia una mayor coherencia de políticas en la lucha contra la pobreza. ¿Qué se está haciendo desde nuestra política económica, comercial, de defensa, para paliar estas situaciones?, ¿qué responsabilidad tenemos en las mismas? 
Actuar. Una vez realizado el análisis anterior, es necesario plasmarlo en acciones y planteamientos concretos. Podemos identificar 3 ámbitos principales para la acción de cara a integrar el elemento migratorio en el trabajo de cooperación al desarrollo:

1. Incorporación efectiva del fenómeno migratorio como un elemento de contexto en el trabajo habitual de cooperación.

2. Puesta en marcha de acciones específicas para acompañar la decisión migratoria: acceso al crédito, formación y generación de empleo, apoyo a la creación de iniciativas productivas y de comercialización, oficinas de información para emigrantes, etc.

3. Respaldo al papel de los migrantes como agentes del desarrollo de sus comunidades de origen: creando incentivos para el uso productivo de las remesas, apoyando la formación de los emigrantes en su país de destino, facilitando opciones de reinserción para los que deseen regresar, etc.

\section{Migraciones y cooperación en la política española}

Hace ya una década, el Congreso de los Diputados reconocía en una Proposición no de Ley que la cooperación al desarrollo era uno de los tres pilares básicos (junto con la integración social y el control de flujos) que debían sustentar la política española de inmigración.

A pesar de ello, la integración en la práctica de estas dos políticas ha sido prácticamente inexistente. Mientras la política de inmigración se ha centrado de una manera casi exclusiva en el control de flujos, la política de cooperación no ha sido capaz de integrar de una manera elaborada el fenómeno migratorio en sus acciones.

Por lo que respecta a la política de inmigración propiamente dicha, el Programa Global de Regulación y Coordinación de la Extranjería y la Inmigración en España (Plan Greco) 2000-2004 incluye por primera vez el codesarrollo como una línea oficial de actuación. Sin embargo, el uso que se hace del concepto es, cuando menos, confuso, puesto que se habla constantemente del "codesarrollo de los países de origen" transmitiendo un concepto de acción unidireccional Norte-Sur que choca con la incipiente doctrina previamente mencionada.

Por otra parte, las referencias al codesarrollo se plantean de partida en relación directa con el retorno de los emigrantes a su país de origen (retorno 
que se asume como un hecho, sin mencionar en este punto la necesaria voluntariedad del mismo), aspecto que como hemos dicho ha sido uno de los más criticados en el caso francés.

Además, el plan suscita serias dudas sobre aspectos concretos de su puesta en práctica, particularmente los relacionados con la distribución de las competencias relativas a la puesta en práctica de las acciones previstas y el papel que en ello va a jugar la Agencia Española de Cooperación Internacional.

En contraste con este esfuerzo, sorprende la escasísima atención prestada al fenómeno migratorio en los documentos oficiales de la cooperación española. Así, debemos remitirnos directamente al Plan Director de Cooperación 2001/2004 (la Ley de Cooperación Internacional para el Desarrollo de 1998 no hace ninguna mención a las migraciones) para encontrar unas primeras y breves referencias oficiales a las migraciones.

En concreto, en el apartado relativo a las prioridades geográficas se indica que "en las estrategias de cooperación se incluirán posibles soluciones al fenómeno de la inmigración". Un poco más adelante, cuando se habla del Magreb como área prioritaria de la cooperación española se indica: "La estabilidad de esta región es primordial para España y para Europa, y para ello es indispensable una estrategia conjunta de desarrollo para la zona que incluya soluciones al preocupante fenómeno de las migraciones". Poco queda ya del esfuerzo que se realiza en el Plan Greco por presentar la inmigración "como fenómeno deseable para España". Del mismo modo, no se hacealusión alguna a las referencias que el Plan de Inmigración hace al papel de la Agencia Española de Cooperación Internacional.

Las escuetas referencias del Plan Director resultan abiertamente insuficientes en cuanto a su planteamiento (en la medida en que resulta imposible elaborar a partir de él ninguna línea específica deactuación), desconexas con respecto a otras líneas de acción del gobierno español y claramente miopes a la hora de abordar el fenómeno migratorio en su complejidad e integrar su potencial como herramienta de desarrollo.

A pesar de las recomendaciones a este respecto incluidas en el dictamen de la Comisión de Cooperación Internacional para el Desarrollo del Congreso de los Diputados relativas al Plan director, el Plan Anual de la Cooperación Española para el año 2001 no ha pasado de incorporar unas pocas referencias genéricas a la necesidad de "prestar atención a los fenómenos migratorios" y atender a la "regulación satisfactoria" del mismo. Se mantiene por tanto una 
visión instrumental de la ayuda que, de no modificarse, está abocada al fracaso.

Más allá de las referencias inexistentes en los documentos oficiales, podemos destacar igualmente algunas ideas relativas a la realidad de la cooperación española en la práctica a la luz del fenómeno migratorio:

- La inmigración sube, la ayuda no. Mientras la llegada de inmigrantes a España en los últimos años ha ido aumentando de manera evidente, la Ayuda Oficial para el Desarrollo de los países de origen permanece estancada.

- No son ciertas las afirmaciones (sobre las que, por otra parte, habría mucho que discutir) de que los principales países emisores de emigrantes a España son los principales receptores de AOD. De hecho, para 1998 y 1999 sólo 1 de los 5 principales países de origen de inmigrantes en España aparece entre los 5 primeros receptores de ayuda (Marruecos en 1998 y República Dominicana en 1999).

- La cooperación española en los principales países de origen de los inmigrantes no está contribuyendo de una manera decidida a generar opciones para los más pobres, en la medida en que nuestra ayuda sigue estrechamente vinculada a los intereses comerciales españoles y muy lejos de prestar una atención suficiente a cubrir las necesidades básicas de la población o a generar nuevas oportunidades para los que están pensando emigrar.

- Hasta el momento, la coordinación de las negociaciones en materia de inmigración y cooperación al desarrollo entre España y los países de origen de inmigrantes ha sido prácticamente inexistente.

- El Gobierno español ha dejado pasar algunas oportunidades relevantes para plantear acciones novedosas e innovadoras de apoyo a algunos de los principales países emisores de emigrantes. Así, en un momento en que los sucesos relativos a los inmigrantes ecuatorianos estaban en plena actualidad, el gobierno rechazó (o, para ser más exactos, nunca llegó a considerar) una propuesta planteada por la campaña Deuda externa, ¿deuda eterna? para liderar un proceso consultivo a nivel internacional en el que se buscasen soluciones para la crisis de la deuda externa ecuatoriana.

Mientras la cooperación oficial permanece prácticamente ajena al debate que planteamos, resulta interesante comprobar cómo van apareciendo, en el ámbito no gubernamental, algunas experiencias puntuales que, progresiva- 
mente, van estableciendo vínculos entre las acciones de inmigración y cooperación. En el ámbito de las ONG de acción internacional podemos destacar los pasos que se están dando en organizaciones como Cáritas (a través del plan "Migración, Comunicación y Desarrollo"), Cruz Roja, Médicos Sin Fronteras o el MPDL (con acciones como el apoyo al establecimiento en España de asociaciones de inmigrantes o la apertura de oficinas en algunos de los países de origen más significativos).

Por su parte, varias de las asociaciones de inmigrantes en España (como Rumiñahui, ATIME, el Colectivo de Inmigrantes Independientes o la Asociación de Jóvenes Luso Africanos de Andalucía) han comenzado a plantearse la necesidad de llevar a cabo proyectos de cooperación con sus comunidades de origen, algunos de los cuales se están poniendo en marcha, generalmente en colaboración con organizaciones locales.

\section{Conclusiones y propuestas para la acción desde la cooperación al desarrollo}

Las complejas vinculaciones entre migraciones y desarrollo suponen un reto que la cooperación internacional debe ser capaz de asumir. Para ello, es preciso evitar mirar la inmigración como una fuente de problemas y la Ayuda al Desarrollo como una herramienta para frenarla. Se hace necesaria una visión más abierta, dispuesta a aprovechar el potencial de las migraciones para luchar contra la pobreza. Mirando en esta dirección, presentamos una serie de recomendaciones y propuestas para los distintos agentes de la cooperación.

- Propuestas para el Gobierno central

- Recuperar el consenso sobre inmigración y asegurar el respeto de los derechos fundamentales a todas las personas, con independencia de su origen o situación legal.

- Mejorar cuantitativa y cualitativamente la Ayuda Oficial al Desarrollo, para que sea una herramienta que genere opciones y que aproveche el potencial de las migraciones en la lucha contra la pobreza.

- Revisar los programas de cooperación en los principales países de origen, analizando si actúan sobre los procesos que acompañan a las migraciones y comprometiendo el destino de un mayor número de 
recursos a las líneas de acción específicamente relacionadas con las migraciones.

- Respaldar la creación de una subcomisión en la Comisión de Cooperación del Congreso, en la que se elaboren propuestas para la integración efectiva de ambas políticas.

- Mantener en la Unión Europea una postura tendente a vincular migraciones y desarrollo. Durante la presidencia española del primer semestre de 2002, incorporar el codesarrollo en la agenda del Consejo de Ministros.

- Propuestas para la cooperación descentralizada

- Coordinar las actuaciones en materia de inmigración y los programas de cooperación, en la misma línea que se plantea para el gobierno central.

- Aprovechar su mayor proximidad al ciudadano para crear espacios de intercambio cultural y fomentar el acercamiento entre los pueblos, el conocimiento y el respeto de las diferentes realidades.

- Respaldar la constitución y el fortalecimiento de asociaciones de inmigrantes en el municipio o comunidad.

- Potenciar la sensibilización y la educación para el desarrollo en nuestra sociedad, utilizando por ejemplo la herramienta del hermanamiento con localidades de origen de algún colectivo relevante de inmigrantes.

- Propuestas para las ONGD

- Avanzar en el proceso de reflexión interna para encontrar el espacio propio de actuación de las ONGD en el contexto de las migraciones, buscando vías de coordinación con otras entidades.

- Colaborar con asociaciones de inmigrantes (prestándoles apoyo para su funcionamiento y trabajando con ellos en la identificación de proyectos específicos), con ONG españolas de inmigración y con otros colectivos como sindicatos, universidades, asociaciones empresariales, etc.

- Actuar en el terreno de la sensibilización y la educación para el desarrollo. 


\section{Bibliografía}

AcostA, A., Deuda externa y migraciones Sur-Norte. El caso de Ecuador, ponencia presentada en el III Seminario Internacional "Deuda Externa: balance y perspectivas de acción para la sociedad civil". Madrid, 4 y 5 de junio de 2001, mimeo.

BACARIA, J . (ed.), Migración y Cooperación mediterráneas. Transferencia de los emigrantes residentes en España e Italia, Barcelona, Institut Català de la Mediterrània d'Estudis i Cooperació, 1998.

Banco Interamericano de Desarrollo, Remittances to Latin America and the Caribbean: comparative statistics, material introductorio para la conferencia "Remittances as a Development Tool: A Regional Conference", Washington, D.C., 17 y 18 de mayo de 2001.

CASAS Álvarez, F. J ., "Emigración, codesarrollo y cooperación para el desarroIlo: reflexiones desde una óptica española", en Migraciones, Instituto Universitario de Estudios sobre Migraciones, $\mathrm{n}$ 0 8, diciembre 2000, Universidad Pontificia de Comillas.

Colectivo loé, "La inmigración extranjera en España, 2000", en VV.AA., La inmigración extranjera en España. Los retos educativos, Colección Estudios Sociales, Núm.1, 2000, Fundación "La Caixa".

Comisión Económica para América Latina y el Caribe - CEPAL, varios Informes de reuniones de expertos sobre remesas en Centroamérica (México, Guatemala, Nicaragua, El Salvador y Honduras) y propuestas para su optimización. 1999-2000.

Congreso de los Diputados, Diarios de Sesiones núm. 147 (13/02/01) y 150 (14/ 02/01) sobre la presentación y debate del Plan de Cooperación.

Congreso de los Diputados, Boletín Oficial de las Cortes Generales, Serie D., Números 138 y 160.

GoYtISOLO, J . y NAïR, S., El peaje de la vida. Integración o rechazo de la emigración en España, Madrid, Aguilar, 2000.

DE HAAN, A., "Migrants, livelihoods and rights: the relevance of migration in development policies", Working Paper, no 4, Londres, DFID, 2000.

Herrero Muñoz-Cobo, B., Codesarrollo: alternativa para la gestión de migraciones y desarrollo. Apuntes para la reflexión y el debate, mimeo. 
MALGESINI, G., Inmigración y cooperación, mimeo.

MAS, F., Rompiendo fronteras. Una visión positiva de la inmigración. Dossiers para entender el mundo, № 10, Barcelona, Intermón Oxfam, 2001

Ministerio de Trabajo y Asuntos Sociales, Anuario de Migraciones 2000.

Naïr, S., Informe de balance y orientación de la política de codesarrollo en relación con los flujos migratorios, París, Misión Interministerial sobre Migración y Codesarrollo, 1997.

PajARes, M., La inmigración en España, Barcelona, Icaria, 1999.

StALKER, P., Workers without Frontiers. The impact of globalization on international migration, Ginebra, Organización Internacional del Trabajo, 2000.

VV.AA, La inmigración dominicana en el tercer milenio, Seminario Internacional celebrado en Santo Domingo en noviembre de 2000, editorial Betania, Colección Ciencias Sociales. 